УДК 81"42

ББК 80

DOI: https://doi.org/10.17308/lic.2021.4/3815

\title{
ТЕКСТОВЫЙ ПЕЙЗАЖНЫЙ КОГНИТИВНЫЙ АТТРАКТОР КАК СРЕДСТВО ПЕРЕДАЧИ ТЕМАТИКИ ХУДОЖЕСТВЕННОГО ПРОИЗВЕДЕНИЯ (НА МАТЕРИАЛЕ РОМАНА Т. КЕНЕЛЛИ «ТНЕ DAUGHTERS OF MARS»)
}

\author{
И. А. Даниленко
}

Белгородский государственный национальный исследовательский университет

\author{
LANDSCAPE TEXT COGNITIVE ATTRACTOR \\ AS A MEANS OF TRANSMITTING THE THEME \\ OF AN ARTISTIC TEXT \\ (BASED ON THE NOVEL BY T. KENELLI "THE DAUGHTERS OF MARS")
}

\author{
I. A. Danilenko \\ Belgorod State National Research University
}

\begin{abstract}
Аннотация: в статье рассматривается концепџия когнитивных текстовых аттракторов в рамках теории текстовых миров. Приводится классификация текстовых когнитивных аттракторов, среди которых особое внимание автор уделяет пейзажному текстовому когнитивному аттрактору. Автор утверждает, что данный вид текстового когнитивного аттрактора обладает значительным потенциалом для передачи тематики художественного произведения. Помещая в пейзажные описания определенные элементы, автор художественного текста подводит читателя к предстоящим событиям, задавая тон всему действию.

Ключевые слова: текстовый когнитивный аттрактор, текстовый пейзажный когнитивный аттрактор, текст, текстовый мир, пейзажные единииь.
\end{abstract}

\begin{abstract}
: the topic of the study is landscape text cognitive attractors a means of transmitting the theme of an artistic text. The subject of the study is landscape text cognitive attractor. The article discusses the concept of cognitive text attractors within the theory of text worlds. The aim of the study is to reveal the possibilities of using landscape text attractors when transmitting a literary text theme. The method used in the work is cognitive-hermeneutic method. An author, creating a text world, is interested in a greater number of readers and, as a consequence, in a greater number of text worlds being created on the basis of his novel. The elements that catch and hold the readers' attention are text cognitive attractors. The author of the article proves that any text landscape cognitive attractor possesses a potential in revealing the text theme. Providing landscape descriptions with certain elements, the author of an artistic text leads the reader to the upcoming events, setting the tone for the whole forthcoming action. The results of the study can be applied within creating courses of lectures in cognitive linguistics, when writing course or qualification works and as the basis for further research.
\end{abstract}

Key words: text cognitive attractor, text landscape cognitive attractor, text, text world, landscape units.

\section{Введение}

Как отмечал в своей работе «Текст как объект лингвистического исследования» И. Р. Гальперин, «текст - это произведение речетворческого процесса, обладающее завершенностью, объективированное в виде письменного документа; произведение, состоящее из названия (заголовка) и ряда особых языковых единиц (сверхфразовых единств), объединенных

(С Даниленко И. А., 2021 
разными типами лексической, грамматической, стилистической связи, имеющих определенную целенаправленность и прагматическую установку» [1, с. 14].

Автор художественного произведения старается увлечь как можно большее количество читающих. Творя мир, населяя его героями и наполняя его событиями, писатель пользуется своим жизненным опытом: он превращает часть своей авторской концептосферы в концептосферу художественного произведения. «Лингвокультурные концепты, связанные с культурой как отдельно взятого народа, так и с общечеловеческой культурой, претерпевая индивидуально-авторскую интерпретацию писателя, интерпретацию, обусловленную когнитивно-сюжетной канвой произведения» [2, с. 133], становятся уже художественными концептами и формируют концептосферу конкретного художественного произведения.

В художественном тексте «вербализуется авторская концептуальная картина мира, при этом особенности языковой личности прямо пропорциональны особенностям ее картины мира» [3, с. 95].

\section{Материалы и методы}

Руководствуясь задачей привлечения наибольшего количества читателей, автор создает концептосферу своего произведения доступной для понимания читателя. Правильное понимание текста - одно из главных условий построения текстового мира. Это явление подробно описано в теории текстовых миров [4], согласно которой текстовый мир творится писателем и читателем в равной степени, а текст - это всего лишь посредник, т. е. «текстовый мир представляет собой концептуальное пространство, которое создают отправитель и получатель, взаимодействуя с текстом» [5, с. 45].

Кроме того, важно, что на создание текстового мира влияет «наличие, и характер фоновых знаний двух субъектов взаимодействия» [6, с. 36]. Если понятие или явление не доступно для читателя, то текстовый мир не будет построен - текст останется непонятым и не вызовет интерес, поскольку индивидуальная составляющая и формирует «интерпретирующие выводы» [7, p. 4] и «интерпретирующие размышления» [8].

В каждом художественном тексте есть лексические единицы, которые служат как элементы привлечения внимания читателя к тексту. Проведенные ранее исследования в области когнитивной лингвистики позволили дать определение и классифицировать многообразие таких элементов текста. Исходя из функций, выполняемых этими элементами, их принято называть «текстовыми когнитивными аттракторами». Текстовые когнитивные аттракторы - это «доминантные смысловые маркеры, посредством которых привлекается и удерживается внимание читателя к сюжету литературно-художественного произведения» [9, с. 87].

Классификация текстовых когнитивных аттракторов была представлена Е. А. Огневой:

1) текстовый проксемный когнитивный аттрактор;

2) текстовый темпоральный когнитивный аттрактор;

3) текстовый пейзажный когнитивный аттрактор;

4) текстовый эмотивный когнитивный аттрактор;

5) текстовый персонажный когнитивный аттракTop;

6) текстовый коллоративный когнитивный аттрактор;

7) текстовый световой когнитивный аттрактор;

8) текстовый сюжетный когнитивный аттрактор $[9$, с. 87].

Каждый конкретный читатель при выборе художественного текста опирается на определенный тип текстового когнитивного аттрактора: читатель интересующийся, скажем, природой определенной местности, выберет текст, в котором действие происходит именно в этой местности. В этом случае выбор текста произойдет на основе когнитивных пейзажных аттракторов. Читатель, интересующийся историей, будет отбирать тексты по когнитивным темпоральным маркерам.

Выбор текста может основываться одновременно на нескольких текстовых когнитивных аттракторах: исторический роман об Англии с определенными историческими личностями. В этом случае выбор текста обусловлен проксемным, персонажным и темпоральным когнитивными аттракторами.

Как следует из определения, текстовые когнитивные аттракторы не только привлекают, но и удерживают внимание читателя. Для этого писателю необходимо распределить аттракторы по тексту относительно равномерно. В противном случае для определенной группы читателей интересна будет лишь часть текста.

Согласно замыслу писателя, в художественный текст закладываются определенные текстовые когнитивные аттракторы, однако читатель может найти для себя такие текстовые когнитивные аттракторы, которые не подразумевались писателем в качестве аттракторов. Таким образом, круг заинтересованных данным текстом читателей может выходить за границы целевой аудитории.

Проведенное исследование по выявлению текстовых когнитивных аттракторов позволило сделать вывод о тематической принадлежности текстовых когнитивных аттракторов. Каждый из вышеперечисленных текстовых когнитивных аттракторов может раскрывать определенную тематику: медицинскую, тему искусства или тему войны. При этом определенная тема может быть реализована как при помощи 
конкретной лексики, к ней относящейся: шприц, скальпель, гипсовая повязка, патрон, гильза, каска, так и при помощи текстовых когнитивных аттракторов имеющих тематическую принадлежность.

В историческом романе о войне обязательно присутствует лексика военной тематики, при этом она не входит в номинативное поле какого-либо из текстовых когнитивных аттракторов, например, лексемы «солдат», «снаряд», «атака» и т. д. В подобном романе их количество настолько велико, что они способны сформировать текстовый тематический когнитивный аттрактор. Текстовый тематический когнитивный аттрактор - это вся совокупность лексических единиц, репрезентирующих определенную тематику, которая служит для привлечения и удержания внимания читателей.

Помимо собственно лексики когнитивного тематического аттрактора (повесть о докторах, роман о военных и т. д.), тематика может реализовываться при помощи других когнитивных текстовых аттракторов имеющих тематическую окраску. Так, текстовый персонажный когнитивный аттрактор может включать в свое номинативное поле главных героев военных, художников или докторов. Рассмотрим нашу гипотезу более подробно на основе текстового пейзажного когнитивного аттрактора, поскольку он обладает наибольшим потенциалом для тематической окраски. Так, городской пейзаж может раскрывать тему искусства, если при описании особое внимание уделено именно архитектурной составляющей, может раскрывать тему одиночества, если описывается мрачный дождливый вечер, может раскрывать военную тематику, если городской пейзаж описывает разрушения города. Кроме того, пейзажные описания часто используются для передачи настроения героев.

«При описании характеров главных героев значимой единицей выступает описание окружающего пространства, ибо действующие лица всегда находятся в том или ином окружении. Дать описание окружающего пространства можно по-разному: в зависимости от душевного состояния героя одни и те же обстоятельства могут трактоваться с различными оттенками, проходя сквозь призму восприятия героя или автора» [10, с. 4].

\section{Результаты исследования}

Чтобы проиллюстрировать возможности использования пейзажных описаний для раскрытия милитарной тематики, нами был выбран роман австралийского писателя Томаса Кенелли «The Daughters of Mars». Роман примечателен тем, что наряду с пейзажными описаниями Австралии и Европы он изобилует пейзажными текстовыми аттракторами, раскрывающими милитарную тематику.
«As the city was crossed, the peaks of the pyramids showed up ahead in a dust-tainted twilight. They had been heavenly creatures from picture books, gigantic entities in everyone's imagination, and it was hard now to believe they were tethered to a specific patch of earth - that they could be casually seen and perhaps approached and then passed by as you'd pass a town... The palmed oasis ahead seemed flat as a stage painting and defied belief too. The road took them into the trees to a flat-roofed mansion with a red cross on its veranda wall. Once a hunting lodge - they'd been told where the kings of Egypt invited their friends to shoot gazelles. More recently a hotel. Now a hospital» [11]Когда они выехали из города, впереди, из пыльного заката показались вершины пирамид. Они, казалось, были не от мира сего, творения с картинок в книге, гигантские сущности в воображении каждого. Теперь трудно было поверить, что они находятся в конкретной части мира, что их можно случайно увидеть, можно даже подойти к ним, а затем даже и пройти мимо, как проходят по городу... пальмовый оазис впереди казался плоским, как декорация, и в его существование тоже трудно было поверить. Дорога привела их к особняку с плоской крышей среди деревьев с красным крестом на стене веранды. Раньше, как говорят, это был охотничий домик, куда правители Египта приглашали своих гостей охотиться на газелей. Еще совсем недавно это был отель, а теперь - госпиталь (здесь и далее перевод наш. - И. Д.)

В данном контексте присутствует только земной пейзаж. Номинанты текстового проксемного аттрактора дополняются номинантами текстового колоративного аттрактора: a dust-tainted twilight- пыльный закат, формируя единое описание. Рассмотренное описание пейзажа не имеет тематической окраски и представляет интерес для читателя только как описание конкретной местности.

В данном контексте выявлены следующие значимые номинанты текстового пейзажного когнитивного аттрактора:

the peaks of the pyramids - вершины пирамид;

heavenly creatures - творения не от мира сего / неземные творения;

gigantic entities - гигантские сущности.

Три представленных номинанта являются семантическим дублированием.

The palmed oasis ahead seemed flat as a stage painting and defied belief too. The road took them into the trees to a flat-roofed mansion with a red cross on its veranda wall - пальмовый оазис впереди казался плоским, как декорация, и в его существование тоже трудно было поверить. Дорога привела их к особняку с плоской крышей среди деревьев с красным крестом на стене веранды. 
Другой контекст. Это отрывок из письма одной из сестер, только что прибывшей из Австралии в Египет:

«The great Canal shone so sharp and blue in the midst of sand and all along encampments of Tommies and Indians - wandering amongst tents - who looked pretty bored and cheered us. In the Bitter Lakes in the middle of the Canal there was a crowd of ships moored there. Then we were back into the arrow-straight canal and came to the shady town of Ismailia - shaded by palm trees, of course I mean. There we moored and came ashore for the first time. A lot of good-looking Arab houses of stone, and mansions people in the know tell me look French. Older Egyptian women dressed in black but urchin girls running around barefoot in orange and yellow and blue tatters. Some women carry big bundles on their heads» [11] - Знаменитый канал (Суэцкий) резко выделялся своим синим цветом среди песков, а по его берегам расположился лагерь «Томми» и индийцев, праздно шатавшихся среди палаток со скучающим видом и приветствовавших нас. В районе Горьких Озер посередине канала сгрудились пришвартованные корабли. Потом мы снова продолжили путь по прямому, как стрела, каналу до тенистого города Исмаилия. Тенистого из-за пальм, конечно же. Там мы пришвартовались и сошли на берег в первый раз. Здесь было много красивых каменных домов в арабском стиле, а жильцы местных особняков - местные всезнайки - принимали меня за француженку. Египтянки постарше носили все черное, а вот босоногие девчонки, бегавшие вокруг, носили оранжевые, желтые и голубые обноски. Некоторые из женщин несли большие тюки на голове.

В данном контексте выявлены следующие лексические единицы номинативного поля текстового проксемного когнитивного аттрактора:

The great Canal - великий канал;

midst of sand - среди песков;

and all along encampments - а по берегам разбит лагерь;

In the Bitter Lakes in the middle of the Canal there was a crowd of ships moored there - В районе Горьких Озер посередине канала сгрудились пришвартованные корабли;

the arrow-straight canal - прямой, как стрела, канал;

shady town of Ismailia - shaded by palm trees - тенистый город Исмаилия, тенистый благодаря пальмам;

a lot of good-looking Arab houses of stone - множество красивых каменных домов в арабском стиле.

В этом описании путешествия по Суэцкому каналу выявлено два вида пейзажей: пейзаж водной поверхности и пейзаж земной поверхности.
Отдельно следует остановиться на номинантах текстового персонажного аттрактора, выявленных в данном контексте:

Tommies and Indians - wandering amongst tents «Томми» и индийцы, праздно шатающиеся среди палаток.

Older Egyptian women dressed in black but urchin girls running around barefoot in orange and yellow and blue tatters. Some women carry big bundles on their heads - Египтянки постарше носили все черное, а вот босоногие девчонки, бегавшие вокруг, носили оранжевые, желтые и голубые обноски. Некоторые из женщин несли большие тюки на голове.

В данное пейзажное описание включены лигвокультуремы. Под лингвокультуремой следует понимать лексические единицы, отражающие в языке понятийную составляющую культуры, это слова с национально-культурным компонентом [12]. Лингвокультуремы - это названия предметов, понятий, концептов одной культуры, которые не встречаются в другой культуре [13].

Несмотря на то, что Томми, индийцы и египтянки являются персонажами, их следует в то же время отнести и к текстовому пейзажному когнитивному аттрактору. Они не являются самостоятельными персонажами, и никак не влияют на сюжет, они лишь создают атмосферу и сеттинг того места, в котором оказалась главная героиня: египтянки - чтобы описать местное колоритное население, Томми и индусы чтобы показать присутствие Британской империи. Как и в предыдущем контексте, лексические единицы, номинирующие этих персонажей, находятся на стыке двух текстовых когнитивных аттракторов - пейзажного и персонажного, и входят в номинативные поля сразу обоих когнитивных текстовых аттракторов.

Рассмотренное описание пейзажа не имеет милитарной тематической окраски.

Другой пример:

«As Southampton had offered so little of ideal Britain, the basin in which they landed at Boulogne offered nothing of France. Though a distant castle could be seen on a rise, it was a mere token. They were separated from it by a vast, squalid railyard, where troops who had arrived fully equipped on earlier ferries waited and smoked by companies and battalions amidst shuttling trains. Here, loneliness in crowds and expectation and fear seemed to create their own odor. Soot lay over all. The absolute khakiness of the mass swamped the few tokens of difference - a group of kilts here, a slouch-hatted Australian there. But chiefly masses of undifferentiated men in steel helmets. And all of them nutriment for cannon» [11] - Как Саутгемптон мало походил на Британию, так Болонь, где они высадились, мало походила на Францию. Несмотря на то, что вдалеке на возвышенности виднелся замок, это мало что меняло. 
Их разделяла большая запущенная железнодорожная станция, где прибывшие на паромах ранее уже в полной экипировке, целыми ротами и батальонами войска, курили, между прибывающими и отходящими поездами. Здесь одиночество среди толпы, надежда и страх, казалось, даже имели свой собственный запах. Все было покрыто сажей. Повсеместный цвет хаки иногда перемежался с другими цветовыми пятнами: здесь - килты, а вот австралийская шляпы с полями. Но в основном - неразличимая масса людей в стальных касках. И все - пушечное мясо.

В данном контексте выявлены следующие лексические единицы номинативного поля текстового проксемного когнитивного аттрактора:

a distant castle could be seen on a rise - вдалеке на возвышенности виднелся замок;

a vast, squalid railyard - большая, запущенная станция;

soot lay over all - все было покрыто сажей.

Помимо лексических единиц, номинирующих объекты окружающего мира, как и в прошлом примере, персонажи также выступают как номинанты текстового проксемного когнитивного аттрактора:

troops fully equipped by companies and battalions amidst shuttling trains - войска в полной экипировке в составе рот и батальонов среди прибывающих и отходящих поездов;

a group of kilts here - группа в килтах здесь;

a slouch-hatted Australian there - там - австралиец в широкополой шляпе;

masses of undifferentiated men in steel helmets неразличимая масса мужчин в стальных касках.

Кроме того, выявлены:

- текстовый ольфакторный когнитивный аттрактор, под которым мы понимаем лексические единицы описывающие запахи в художественном тексте-loneliness in crowds and expectation and fear seemed to create their own odor - одиночество среди толпы, надежды и страх, казалось, даже имели свой собственный запах;

- синергия текстовых колоративного и проксемного когнитивных аттракторов - the absolute khaki$n e s s$ - повсеместный цвет хаки.

В отличие от первых двух контекстов, последний имеет ярко выраженную тематическую окраску - милитарный пейзаж. Благодаря наличию в пейзаже элементов милитарного характера, описание перестает быть простым пейзажем земной поверхности и становится тематическим.

\section{Заключение}

Подобным образом тематическую окраску может получить и любой другой текстовый когнитивный аттрактор. Так выявленный текстовый колоративный когнитивный аттрактор - the absolute khakiness (по- всеместный цвет хаки) явно подразумевает цвет военных мундиров, поэтому можно с уверенностью говорить, что данный колоративный аттрактор, так же как и проксемный, имеет тематическую окраску.

Любой текстовый когнитивный аттрактор может принимать тематическую окраску в зависимости от интенции писателя, привлекая и удерживая тем самым внимание определенной группы читателей.

\section{ЛИТЕРАТУРА}

1. Гальперин И. Р. Текст как объект лингвистического исследования. М., 2008. 144 с.

2. Огнева Е. А., Гусакова Н. Л. Специфика структуры текстовой лингвокультурной доминанты (на материале произведения Э. Бронте «Wuthering Heights») // Филологические науки. Вопросы теории и практики. Тамбов, 2016. № 6-2 (60). С. 133-135.

3. Попова T. Г. Художественная картина мира как концептуализированное художественное пространство // Язык и культура в эпоху глобализации : сб. науч. трудов : в 2 т. СПб. : Изд-во СПбГЭУ, 2013. Т. 2, вып. 1. С. 95-97.

4. Werth P. Text Worlds : Representing Conceptual Space in Discourse. London : Longman, 1999.

5. Кушнерук С. Л. Теория текстовых миров как исследовательская программа в рамках когнитивной лингвистики // Вопросы когнитивной лингвистики. 2011. № 1. С. $45-51$.

6. Даниленко И. А. Этапы создания текстового мира на примере произведения Ф. С. Фитцджеральда «Tender is the hight» // Лингвистические горизонты : сб. материалов V Междунар. науч.-практ. конф. Белгород, 2017. C. $35-39$.

7. McCarthy K.S. Reading beyond the lines. A critical review of cognitive approaches to literary interpretation and comprehension // Scientific study of literature. 2015. No. 5. C. 99-128.

8. McCarthy K. S. and Goldman S. R. Constructing interpretive inferences about literary text : the role of domain-specific knowledge. Chicago, USA : University of Illinois at Chicago, 2017.

9. Огнева $E$. A. Концепция текстовой когнитивной аттракции // Лингвистические горизонты : междунар. сб. науч. трудов / отв. ред. Е. А. Огнева, И. Б. Акиншина. Белгород : Эпицентр, 2018. Вып. VI. С. 87-92.

10. Даниленко И. А. Роль пейзажных единиц в номинативном поле дуального концепта «Любовь и одиночество» (на материале романа Ф. С. Фицджеральда «Тhe Great Gatsby» («Великий Гетсби») // Научный результат. Вопросы теоретической и прикладной лингвистики. 2016. T. 2, № 4 (10). C. 3-8.

11. Keneally T. The Daughters of Mars : a Novel. Vintage, Australia. 2012. URL: https://www.rulit.me/books/ the-daughters-of-mars-download-308336.html

12. Верещзагин Е. М., Костомаров В. Г. Язык и культура. М., 1976. 248 c.

13. Веденина Л. Г. Теория межкультурной коммуникации и значение слова // Иностранные языки в школе. 2000. №. 5. C. $72-80$. 


\section{REFERENCES}

1. Gal'perin I. R. Tekst kak ob"ekt lingvisticheskogo issledovaniya [Text as an object of linguistic research]. M., 2008. 144 p.

2. Ogneva E. A., Gusakova N. L. Spetsifika struktury tekstovoj lingvokul'turnoj dominanty (na materiale proizvedeniya EH. Bronte «Wuthering Heights») [The specifics of the structure of the textual linguocultural dominant (based on the work of E. Bronte "Wuthering Heights"]. In: Filologicheskie nauki. Voprosy teorii i praktiki. Tambov, 2016. No. 6-2 (60). Pp. 133-135.

3. Popova T. G. Khudozhestvennaya kartina mira kak kontseptualizirovannoe khudozhestvennoe prostranstvo [Artistic picture of the world as a conceptualized art space]. In: Yazyk i kul'tura v ehpokhu globalizatsii: sb. nauch. tr. v 2 tomakh. SPb.: Izd-vo SPbGEHU, 2013. T. 2. Vyp. 1. Pp. 95-97.

4. Werth P. Text Worlds: Representing Conceptual Space in Discourse London : Longman, 1999.

5. Kushneruk S. L. Teoriya tekstovykh mirov kak issledovatel'skaya programma v ramkakh kognitivnoj lingvistiki [The theory of text worlds as a research program in the framework of cognitive linguistics]. In: Voprosy kognitivnoj lingvistiki. 2011. No. 1. Pp. 45-51.

6. Danilenko I. A. Ehtapy sozdaniya tekstovogo mira na primere proizvedeniya F. S. Fittsdzheral'da «Tender is the hight» [Stages of a text world creating based on F. S. Fitzgerald's «Tender is the hight»]. In: Lingvisticheskie gorizonty: Sbornik materialov V Mezhdunar. nauch.-prakt. konf. Belgorod, 2017. Pp. 35-39.

Белгородский государственный национальный исследовательский университет

Даниленко И. А., дочент кафедры иностранных языков педагогического института

E-mail: danilenko_ia@bsu.edu.ru

Поступила в редакичюю 23 июля 2021 г.

Принята к публикачии 15 октября 20212.

\section{Для цитирования:}

Даниленко И. А. Текстовый пейзажный когнитивный аттрактор как средство передачи тематики художественного произведения (на материале романа Т. Кенелли «The Daughters of Mars») // Вестник Воронежского государственного университета. Серия: Лингвистика и межкультурная коммуникация. 2021. № 4. С. 90-95. DOI: https://doi.org/10.17308/lic.2021.4/3815
7. McCarthy K. S. Reading beyond the lines. A critical review of cognitive approaches to literary interpretation and comprehension. In: Scientific study of literature. 2015. No. 5. Pp. 99-128.

8. McCarthy K. S. and Goldman S. R. Constructing interpretive inferences about literary text: The role of domain-specific knowledge, Chicago, USA: University of Illinois at Chicago, 2017.

9. Ogneva E. A. Kontseptsiya tekstovoj kognitivnoj attraktsii [The concept of textual cognitive attraction]. In: Lingvisticheskie gorizonty: mezhdunar. sb. nauch. tr. Otv. red. E. A. Ogneva, I. B. Akinshina. Belgorod: Ehpitsentr, 2018. Vyp. VI. Pp. 87-92.

10. Danilenko I. A. Rol' pejzazhnykh edinits v nominativnom pole dual'nogo kontsepta "Lyubov' $i$ odinochestvo» (na materiale romana $F$. C. Fitsdzheral'da «The Great Gatsby» / "Velikij Getsbi») [The role of landscape units in the nominative field of the dual concept "Love and loneliness" (based on the novel by F. C. Fitzgerald "The Great Gatsby"]. In: Nauchnyj rezul'tat. Voprosy teoreticheskoj $i$ prikladnoj lingvistiki. 2016. T. 2, No. 4 (10). Pp. 3-8.

11. Keneally T. The Daughters of Mars: A Novel. Vintage, Australia. 2012. Available at: https://www.rulit.me/ books/the-daughters-of-mars-download-308336.html

12. Vereshhagin E. M., Kostomarov V. G. Yazyk i kul'tura [Language and culture]. M., 1976. 248 p.

13. Vedenina L. G. Teoriya mezhkul'turnoj kommunikatsii $i$ znachenie slova [Theory of intercultural communication and word meaning]. In: Inostrannye yazyki v shkole. 2000. No. 5. Pp. 72-80.

Belgorod State National Research University Danilenko I. A., Associate Professor of the Foreign Languages Department of the Pedagogical Institute

E-mail: danilenko_ia@bsu.edu.ru

Received: 8 July 2021

Accepted: 15 October 2021

\section{For citation:}

Danilenko I. A. Landscape text cognitive attractor as a means of transmitting the theme of an artistic text (based on the novel by T. Kenelli "The Daughters of Mars"). Proceedings of Voronezh State University. Series: Linguistics and Intercultural Communication. 2021. No. 4. Pp. 90-95. DOI: https://doi.org/10.17308/lic.2021.4/3815 